Pobrane z czasopisma Wschód Europy http://journals.umcs.pl/we

Data: 26/04/2023 15:58:18

DOl:10.17951/we.2018.4.2.157.

Wschód Europy • Восток Европы • East of Europe vol 4, 2 / 2018

Роман Савенков

ORCID ID: https://orcid.org/0000-0002-1643-2444

Воронежский государственный университет, Россия

\title{
Общественное движение Алексея Навального в России: ресурсы, тактика и перспективы
}

В течение 2017 г. российский политик Алексей Навальный создал широкую сеть региональных организаций во всех крупных городах России, которая оказалась способна к проведению протестных акций всероссийского масштаба. Федеральный уровень публичных мероприятий позволял А. Навальному претендовать на образ единственного эффективного оппонента действующего режима. Личные критические видео-обращения политика в адрес представителей политической и экономической элиты вынуждали последних реагировать в информационном пространстве, публиковать свои видео-ответы. Все это позволяет обозначить движение А. Навального референтной политической организацией, с устойчивой структурой и постоянным (но немногочисленным) ядром сторонников. Целью статьи является анализ целей, ресурсов, тактики движения А. Навального в 2017-2018 гг., анализ тактики властей, а также перспектив протестного движения как субъекта оппозиционной политической деятельности.

Наиболее полное определение социального движения мы находим у С. Тэрроу, которыйназывает социальным движением коллективное действие, стремящееся разрешить коллективные проблемы, основанное на общих целях и социальной солидарности, включающее устойчивое взаимодействие с элитами, оппонентами и властью. Другими словами, социальное движение обладает следующими свойствами: коллективная проблема; общая цель, социальная солидарность и устойчивое взаимодействие ${ }^{1}$. Практически все названные признаки проявились в движении А. Навального.

Генезис движения А. Навального можно разделить на четыре этапа:

I - этап - декабрь 2016 - 12 июня 2017 г. - создание сети штабов в крупных городах, мобилизация граждан к участию в общероссийских публичных

1 S. G. Tarrow, Power in Movement. Social Movement and Contentious Politics, Cambridge University Press, 2011, p. 7-8. 
мероприятиях в поддержку антикоррупционных требований, формирование базы сторонников;

II - июнь 2017 г. - декабрь 2017 г. - переход от антикоррупционной тематики к требованиям выдвижения А. Навального кандидатом в Президенты России, расширение сети штабов до 81 города;

III - декабрь 2017 - март 2018 г. - акция «Бойкот выборов» и подготовка наблюдателей в день голосования;

IV - март 2018 - ноябрь 2018 г. - снижение количества штабов, проведение акций (как правило, в социальных сетях) по локальным проблемам, организация общероссийских митингов «Он нам не царь» и против повышения пенсионного возраста;

V - ноябрь 2018 г. - запуск акции «Умное голосование».

\section{Цель движения}

Участники движения в поддержку А. Навального не называли себя социальным движением, предпочитая термин «общественная кампания». Действительно, движение на первом этапе не озвучивало свои стратегические цели - лишь одну тактическую - поддержка выдвижения А. Навального в качестве альтернативного и конкурентоспособного кандидата на выборах Президента РФ. Будущее движения должно было быть определено по итогам оценки избирателей А. Навального после выборов. Такое сужение цели, с одной стороны, не давало возможности активистам планировать своё будущее, но, с другой стороны, избранный лозунг кампании позволял сплотить под одной фамилией самых разных оппонентов существующего политического режима. Формально Алексей Навальный не мог участвовать в марте 2018 г. в выборах Президента, т.к. в 2013 году он был признан виновным в хищениях по делу «Кировлес» и осужден на 5 лет условно. Условный срок дает возможность свободно передвигаться по стране и продолжать политическую и общественную деятельность, но ограничивает пассивное избирательное право. 25 декабря 2017 г. Центральная избирательная комиссия России на этом основании отказала А. Навальному в регистрации кандидатом в Президенты страны².

На третьем этапе целью движения стало снижение явки на выборах Президента РФ и подготовка наблюдателей ${ }^{3} . \mathrm{B}$ соответствии с законодательством наблюдателей на избирательные участки могли направить зарегистрированные кандидаты, политические партии, выдвинувшие зарегистрированного канди-

2 Постановление Центральной избирательной комиссии Российской Федерации от 25.12.2017 2. №118/973-7 «Об отказе в регистрации группь избирателей, созданной для поддержки самовыдвижения кандидата на должность Президента Российской Федерации Алексея Анатольевича Навального, и его уполномоченных представителей, Официальный сайт ЦИК PФ, http://www.cikrf.ru/activity/docs/postanovleniya/30868/, 25.12.2018.

3 Навальный 20!8, https://2018.navalny.com, 25.12.2018. 
дата и Общественная палата РФ (общественная палата субъекта Федерации) 4 Такое требование законодательства вынудило активных участников движения проводить переговоры с региональными отделениями партий и регистрировать наблюдателей от их имени (как правило, КПРФ и Яблоко).

На четвертом этапе движение некоторое время не имело общей цели, организуя в городах акции, привлекающие внимание к местным проблемам. С ноября 2018 г. запущен проект «Умное голосование», целью которого является поддержка на региональных и муниципальных выборах самого сильного оппозиционного кандидата, определенного движением, с целью не допустить избрания кандидатов от партии «Единая Россия» 5 .

\section{Ресурсы движения}

Организация. В общественную кампанию по поддержке А. Навального к концу третьего этапа включился 81 штаб в городах России (как финансируемых «головным офисом», так и 11 штабов с самостоятельным финансированием). Лидер движения считает создание региональной сети штабов своим главным достижением. При этом большая их часть сохранилась после досрочного завершения оппозиционером собственной президентской кампании. В настоящее время на их базе созданы «политические центры» ${ }^{6}$.Региональные штабы проводили предварительный сбор персональных данных граждан для оперативного сбора подписей при начале процедуры регистрации в качестве кандидата. По данным сайта А. Навального, получено согласие от 648 тыс. граждан, желающих его выдвижения ${ }^{7}$. Ha IV этапе количество штабов сократилось до 46, из них 11 на самостоятельном финансировании.

Активисты и симпатизанты. Большая часть участников движения на первых этапах -это молодые люди в возрасте от 16 до 22 лет. Для этой категории волонтеров в штабахорганизовывались досуговые и просветительские мероприятия. По данным портала «Навальный - 2018», в коллективное действие включилось почти 200 тыс. волонтёров.В тоже время, нельзя переоценивать популярность политика в масштабах всей страны: ютуб-канал Алексея Навального просматривают около 2,2 млн. пользователей Интернет, а это только 1,5\% населения. В то же время аудитория В. Соловьева или Д. Киселева на ТВ - 40-50\% россиян 8 . В конце 2018 г. аудитория канала Навальный LIVE выросла до 6 млн. зрителей9 .

4 П. 8, ст. 23, Федеральный закон от 10.01.2003 №19-Ф3 «О выборах Президента Российской Федерации».

5 Умное голосование, https://2019.vote, 25.12.2018.

6 Иван Родин, Штабы Навального стали политическими иентрами, „Независимая газета”, 09.01.2019, http://www.ng.ru/politics/2019-01-09/1_7477_navalny.html, 11.01.2019.

7 Навальный 20!8, https://2018.navalny.com, 25.12.2018.

8 Денис Волков, Не только большие протестьь, „Ведомости”, 06.05.2018, https://www.vedomosti. ru/opinion/articles/2018/05/07/768724-ne-bolshie-protesti, 10.06 .2018

9 Навальный LIVE-2019. Что с женской аудиторией?, https://navalny.com, 10.01.2019. 
Финансы. По данным интернет-портала А. Навального,за полтора года (с декабря 2016 г.) путем пожертвований было собрано 368 млн. руб. Это крупная сумма для политической организации. К примеру, крупнейшая оппозиционная парламентская партия «КПРФ» в 2017 г. собрала в виде пожертвований от физических лиц 11 млн. руб. а в виде членских взносов $-96,9$ млн. руб. ${ }^{10}$

Лидер. За период активной информационной кампании движению удалось повысить узнаваемость А. Навального, создать ему яркий образ самого успешного и популярного критика действующего режима среди жителей крупных городов. Личные выступления А. Навального собирают относительно большие аудитории, вдохновляют молодежь.Однако, без его личного участия нестоличные штабы часто теряли динамику и активность, слабела мотивация участников движения.

По данным Левада-Центра, после акции 12 июня 2017 г., проведенной в большинстве городов несанкционированно,узнаваемость А. Навального не изменилась (слышали о нём и митингах около 50\%), но считали политика защитником интересов России только 12\%. 39\% респондентов поддержали участников митингов 12 июня, против 37\% неподдержавших. Важный сигнал для власти по итогам массовых задержаний состоит в том, что $40 \%$ считают действия полиции адекватными, в рамках полномочий (не согласны с этим тезисом - 27\% ${ }^{11}$. По данным ВЦИОМ доверие к А. Навальному в конце 2018 г. колебалось в пределах $1,1-1,4 \%$, в то время как уровень недоверия $1,7-2,5 \%{ }^{12}$.

Союзники. Оппозиционные непарламентские группы конкурируют между собой за протестный электорат. Большинство лидеров демократического движения не готово безоговорочно поддержать амбиции А. Навального на лидерство в оппозиционном лагере. Его конкурентом в борьбе за внимание протестного городского электората в период президентской кампании стала телеведущая Ксения Собчак, которая 18 октября 2017 г. объявила о своем желании участвовать в президентских выборах. В открытом письме «светская львица» пообещала снять свою кандидатуру в пользу А. Навального, если его зарегистрируют. Сам А. Навальный осенью 2017 г. попытался не входить в конфронтацию со своим потенциальным конкурентом ${ }^{13}$. Однако, политик жестко отреагировал на ини-

10 Сводные финансовые отчеты политических партий за 2017 год, Центральная избирательная комиссия Российской Федерации, http://cikrf.ru/politparty/finance/svodn_otchet_17.php, 10.01.2019.

11 Июньские протесты не добавили Навальному популярности, 17.07.2017, Левада-Центр, https://www.levada.ru/2017/07/17/iyunskie-protesty-ne-dobavili-navalnomu-populyarnosti/, 25.12.2018.

12 Доверие политикам, Рейтинги и индексы Всероссийского центра изучения общественного мнения (ВЦИОМ), https://wciom.ru/news/ratings/doverie_politikam/, 10.01.2019.

13 Елена Махаметшина, Навальный прокомментировал выдвижение Собчак в президенты, „Ведомости”, 26.10.2017, https://www.vedomosti.ru/politics/articles/2017/10/26/739569-navalniisobchak, 10.12.2018. 
Pobrane z czasopisma Wschód Europy http://journals.umcs.pl/we

Data: 26/04/2023 15:58:18

Общественное движение Алексея Навального в России: ресурсы, тактика и перспективы

циативу К. Собчак объединиться после выборов: Навальный обвинил Собчак в намеренной имитации своей оппозиционности ${ }^{14}$. По нашему мнению,сближение с К. Собчакраскололо бы молодежный протестный городской сегмент и оттолкнуло потенциальных сторонников Навального среднего возраста, не доверяющих К. Собчак.

\section{Тактика движения и реакция властей}

На протяжении 2017-2018 гг. движение А. Навального организовывало проведениесеми всероссийских акций, между которыми региональные штабы проводили локальные акции в поддержку выдвижения А. Навального кандидатом в президенты России или по привлечению внимания к местным проблемам.

Участники первой, самой многочисленной акции 26 марта 2017 г. требовали от властей юридической оценки обвинений премьер-министра России Д. Медведева в коррупции, озвученных в фильме «Он вам не Димон». В большинстве городов акции не были согласованы к проведению в центре города, поэтому они прошли либо как несанкционированные, либо в гайд-парках ${ }^{15}$. Например, в Курске прошли задержания участников несогласованного публичного мероприятия. В Липецке активисты без происшествий организовали прогулку в парке без лозунгов и плакатов. В Белгороде организатору акции в гайд-паркесуд первой инстанции вынес административное наказание за повреждение тротуарной плитки в виде 50 часов общественных работ, которое позднее было отменено областным судом.

Акции протеста 12 июня собрали меньшее количество сторонников А. Навального, которые продолжали требовать реакции правоохранительных органов на обвинения в коррупции Д. Медведева, а также требовали отставки Президента РФ В. Путина. Особенностью этой акции стало её проведение в несогласованном месте в Москве и Санкт-Петербурге, что привело к массовым задержаниям в столицах (более полутора тысяч человек) за нарушение правил проведения публичных мероприятий и сопротивление властям. Участники акций в столицах явно провоцировали власти на жесткие действия. В Белгороде, Воронеже, Курске акции были согласованы, прошли без происшествий. В Липецке (одиночный пикет) и Тамбове акции состоялись как несогласованные. В Тамбове статус гайд-парков присвоили отдаленным городским территориям, «отодвинув» их от центра города.

Со второй половины 2017 г. региональные штабы А. Навального проводили локальные акции по поддержке выдвижения своего лидера кандидатом в Президенты России. Большинство акций проводилось в рамках действующего законо-

14 Дебаты Навального и Собчак, 18.03.2018, https://www.youtube.com/watch?v=gQeAy2ytMnU, 20.03.2018.

15 Кремль на развилке, 26.03.2017, РБК, https://www.rbc.ru/politics/26/03/2017/58d7c6f39a79474 48a1a3f45, 10.01.2019. 
дательства, существующих политических возможностей и представляли собой пикеты с использованием быстровозводимых сборно-разборных конструкций и раздачей листовок. Муниципальные власти запретили работу таких точек на спорном основании нарушения избирательного законодательства. В центральном макрорегионе активность штабов А. Навального разная: в Курске штаб работал с августа 2017 г. по март 2018 г., в Старом Осколе (Белгородская область) с сентября 2017 г. по март 2018 г. В Воронеже и Липецке штабы созданы в апреле, в Тамбове в мае 2018 г. После марта 2018 г. полноценный штаб остался только в Воронеже.

После акции 12 июня 2017 г. изменилась тактика правоохранительных органов: с лидерами региональных штабов стали проводить беседы, изымать оргтехнику (Белгородская область, январь 2018 г.), проводить обыски в штабах в рамках проверок по неполитическим вопросам (Воронеж, Липецк и Тамбов).

Акции протеста 7 октября 2017 г. в городах собрали ещё меньше сторонников, чем две предыдущие.Задержано, в общей сложности, почти 300 человек, т.к. в большинстве городов мероприятия не были согласованы. Основное требование протестующих - допустить А. Навального (находящегося в эти дни под административным арестом) к выборам Президента России в марте 2018 г. В Липецке во время «прогулки» задержано 23 человека, в Тамбове координатор штаба был привлечен к административной ответственности из-за организации несогласованного публичного мероприятия. В октябре А. Навальный выступал в Липецке и Тамбове.

Выдвижение А. Навального было проведено в виде коллективной акции в 20 городах 24 декабря 2017 г., в которой, по оценке самого А. Навального приняло участие более 15 тыс. человек ${ }^{16}$. После отказа ЦИК зарегистрировать Алексея Навального кандидатом в президенты России, его движение готовило наблюдателей на выборах и призвало своих сторонников бойкотировать голосование. 28 января в преддверии президентских выборов сторонники Навального в разных городах вышли на «Забастовку избирателей». Власти Москвы и Санкт-Петербурга эти акции не согласовывали. По итогам мероприятий в 16 городах были задержаны более 300 участников митингов. А. Навальный был арестован на 30 суток за организацию этого мероприятия 25 августа 2018 г. ${ }^{17}$ В целом, активность сторонников А. Навального снижается: на окраинах Белгорода и Тамбова собралось соответственно 100 и 200 чел., в гайд-парке в центре Воронежа - 100 чел. Из центральных регионов только в Липецке два организатора наказаны административным арестом на 20 суток по итогам несогласованной акции.

Протестная акция «Он нам не царь» 5 мая 2018 г., приуроченная к инаугурации Владимира Путина, прошла в большинстве городов с нарушениями дей-

16 Навальный 20!8, https://2018.navalny.com, 25.12.2018.

17 Навального арестовали на 30 суток, РБК, 27.08.2018, https://www.rbc.ru/society/27/08/2018/ 5b83a57b9a7947543b7aa26f?from=main, 25.12.2018. 
ствующего законодательства, что привело, по неофициальным данным, к задержаниям более 1000 участников ${ }^{18}$. В Москве прошли столкновения участников движения с гражданами в форме «казаков». Официальный интернет-портал Центрального казачьего войска (ЦКВ) заявил о неучастии казаков ЦКВ в охране правопорядка и противоправных действиях в этот день ${ }^{19}$. В Центрально-Черноземном регионе без задержаний несанкционированные акции прошли только в Липецке. В Белгороде и Старом Осколе акции были согласованы на окраинах, но организаторов привлекли к административной ответственности. Во время проведения несогласованных акций были задержаны координаторы (Тамбов), а также активные участники (Воронеж и Курск).

9 сентября движение провело Единый день протеста против повышения пенсионного возраста одновременно с Едином днем голосования по избранию глав 26 субъектов Федерации и депутатов законодательных (представительных) органов власти в 17 субъектах Федерации. Акция прошла незамеченной для политиков и СМИ.

Реакция властей на мероприятия А. Навального единая, но имеет некоторые региональные отличия. В связи с тем, что А. Навальный является «знаменем» движения, он регулярно задерживается за совершение административных правонарушений, проведя в под арестом в 2018 г. общей сложности 3 месяца ${ }^{20}$. В регионах представители правоохранительных органов оказывали силовое правовое воздействие: проводили обыски в штабах, задержания активистов движения, неформальные беседы, изъятие агитационных материалов в рамках мероприятий по профилактике экстремизма, противодействия торговле наркотиками. Формально власти действовали в рамках своих полномочий и не предъявляли участникам движения политических обвинений. Центральная линия прогосударственных СМИ - игнорировать мероприятия А. Навального, не давать ему повода стать героем новостных лент. Муниципальные власти, как правило, не согласовывали проведение протестных акций в гайд-парках в центре городов, предлагая альтернативные площадки на окраинах.

\section{Перспективы движения}

На начальных этапах движение А. Навального мобилизовало городскуюпротестную молодежь (в возрасте от 16 до 35 лет), активных пользователей сети Интернет. Движение активно пользуется всемирной сетью и социальными сетями, но не имеет выхода на федеральные информационные каналы. Движение отличается грамотным менеджментом, стремлением стать точкой притяжения

18 Александр Литой, Акции против «иаря»: избитые, задержанные, несовершеннолетние, ОВД Инфо, 08.05.2018, https://ovdinfo.org/articles/2018/05/08/akcii-protiv-carya-izbitye-zaderzhannyenesovershennoletnie, 10.05.2018.

19 Официальный портал Центрального казачьего войска, 07.05.2018, http://vko-ckv.ru/novosti/ ofitsialno.html, 10.01.2019.

20 Итоги-2018, https://navalny.com, 10.01.2019. 
оппозиционных и протестных настроений и конвертировать их в политические дивиденды для своего лидера - Алексея Навального.

По данным Левада-Центра, 71\% респондентов не поддержали акцию против избрания В. Путина на новый президентский срок 5 мая 2018 г. ${ }^{21} \mathrm{He}$ удалось продемонстрировать рядовым гражданам результативность протестных действий в период утверждения пенсионной реформы (август-сентябрь 2018 г.), которую публично поддержал президент ${ }^{22}$. По результатам качественных социологических исследований, россияне настроены на законное и уважительное отстаивание своих прав и интересов ${ }^{23}$. При таких общественных настроениях логичным выглядит снижение «митинговой» активности и запуск Навальным проекта «Умное голосование». Политик приглашает поддержать на выборах регионального и муниципального уровня сильнейшего кандидата (независимо от личных политических симпатий) с целью не допустить победы кандидатов от партии «Единая Россия». Сильного кандидата команда Навального планирует определять путем анализа результатов предыдущих выборов и текущих социологических опросов. Для участия в проекте необходима электронная регистрация на соответствующей платформе ${ }^{24}$. Нарушения правил сбора и обработки персональных данных стали поводом для временной блокировки сайта Роскомнадзором ${ }^{25}$.

Запуск проекта «Умное голосование» дает возможность А. Навальному вернуть себе образ «главного оппозиционера» страны, вокруг которого должны объединяться политические противники правящего класса. Однако реализация проекта столкнется с множеством технических и политических сложностей. Скорее всего, проект направлен не на всю страну, а на крупные города, в первую очередь Москву и Санкт-Петербург. «Умное голосование» не расширяет социальный сегмент поддержки Навального, но «отбирает» минимальный электорат у зарегистрированных политических партий. Опыт создания Координационного совета оппозиции в 2012 г. показал, что оппозиционные группы пока не способны к согласованному политическому действию. Одновременно руководство партии «Единая Россия» начало обновление и ребрендинг партии ${ }^{26}$, а значит мо-

21 Протесты 5-го мая, Левада-Центр, 06.06.2018, https://www.levada.ru/2018/06/06/protesty-5go-maya/, 10.01.2019.

22 Путин объявил о смягчении условий пенсионной реформы, „Ведомости”, 29.08.2018, https:// www.vedomosti.ru/economics/articles/2018/08/29/779297-putin-teleobraschenie, 10.01.2019.

23 М. Дмитриев, С.Белановский, А.Никольская,Признаки изменения общественных настроений и их возможные последствия, Комитет гражданских инициатив, 11.10.2018, https://komitetgi. ru/news/news/3902/,10.01.2019;Осенний перелом в сознании россиян: мимолетный всплеск или новая тенденция?, Фонд «Либеральная миссия», 26.12.2018, http://www.liberal.ru/articles/7298, 10.01.2019.

24 Умное голосование, https://2019.vote, 10.01.2019.

25 Михаил Баринов, Навальный привлечен в качестве третьего лиия киску о блокировке «Умного голосования», 14.12.2018, https://www.kommersant.ru/doc/3832979, 10.01.2019.

26 ХVIII Съезд «Единой России», 9.12.2018, https://er.ru/core/news/subject/145.html, 10.01.2019. 
дернизирует систему отбора кандидатов и взаимодействие с системными оппозиционными силами.

С другой стороны, в условиях ухудшения социального самочувствия ${ }^{27}$, стремления граждан выражать свою политическую позицию легальными, уважительными способами ${ }^{28}$ - возбуждение интереса и доверия к электоральному участию могут стать приемлемой для граждан (особенно среднего возраста) формой политического действия.

\section{Выводы}

Общероссийское движение Алексея Навального в 2017-2018 гг. стало значимой политической организацией с устойчивой структурой и постоянным ядром сторонников. А. Навальный остается оригинальным политиком, с интересными идеями, обладающим способностью выходить за привычные правила политической игры. Оригинальные идеи политика не только привлекают к нему симпатизантов, но и формируют социально однородный сегмент его критиков. «Ахиллесовой пятой» Навального остаются ограничение его личного пассивного избирательного права и отсутствие собственной политической партии. Названные факторы лишают его возможности выйти за пределы уличной (митинговой) активности и заняться борьбой за позиции в органах власти, стать полноценным субъектом политической оппозиции.

В условиях возрождения некоторых элементов публичной политики ${ }^{29}$, победы оппозиционных кандидатов на губернаторских выборах в четырех регионах в сентябре 2018 г., новый проект Навального «Умное голосование» может компенсировать его «слабости» как политика. Однако заявленная полноценная реализация проекта выглядит трудноосуществимой: для мониторинга выборного процесса на всех выборах 2019 г. необходимы финансовые и организационные ресурсы, а также готовность оппозиционных политиков к компромиссу.

В целом, социальный протест стал неотъемлемой частью российского общества, частью повседневной жизни россиян ${ }^{30}$. С 2018 года растет декларируемая готовность граждан к протесту, а эксперты фиксируют среднесрочные факторы

27 Мониторинг самочувствия регионов: ситуация на июль 2018 г. и её развитие, Комитет гражданских инициатив, https://komitetgi.ru/analytics/3946/, Эксперты КГИ представили итоги мониторинга социально-экономической и политической напряженности регионов за mри года, Комитет гражданских инициатив, 20.06.2018, https://komitetgi.ru/analytics/3797/, 10.01.2019

28 Осенний перелом в сознании россиян: мимолетный всплеск или новая тенденция?, Фонд «Либеральная миссия», 26.12.2018, http://www.liberal.ru/articles/7298, 10.01.2019.

29 Николай Петров, Политические переменные: с чем столкнется российская власть в 2019 годy, 06.01.2019, РБК, https://www.rbc.ru/opinions/politics/06/01/2019/5c2491e49a794778e75 8e398, 10.01.2019.

30 Рост протестной активности в России: результаты всероссийского мониторинга 2017-2018 z2., Центр экономических и политических реформ, http://cepr.su/2018/11/08/protests-2017-2018/ 
Pobrane z czasopisma Wschód Europy http://journals.umcs.pl/we

Data: 26/04/2023 15:58:18

накопления социально-экономической и политической напряженности. В условиях сужения возможностей для легального публичного протестного действия возможно ожидать перехода протеста в непубличные формы. Тем более, что в общественном сознании произошли перемены, благоприятствующие поддержке протестного действия.

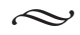

Аннотация: Статья посвящена анализу ресурсов, тактике и перспективам социального движения Алексея Навального в 2017-2018 гг. Описываются и оцениваются основные акции движения и реакция на них властей.

Ключевые слова: протест, политический протест, коллективное действие, Навальный, социальное движение

\section{Ruch społeczny Aleksieja Nawalnego w Rosji: zasoby, taktyka i perspektywy}

Streszczenie: Artykuł jest poświęcony analizie zasobów, taktyk i perspektyw ruchu społecznego Aleksieja Nawalnego w latach 2017-2018. Główne działania ruchu i reakcja władz na nie są opisane i ocenione.

Stowa kluczowe: protest, protest polityczny, akcja zbiorowa, Aleksiej Nawalny, ruch społeczny

\section{Alexei Navalny's Social Movement in Russia: Resources, Tactics and Perspectives}

Abstract: The article is devoted to the analysis of resources, tactics and prospects of the social movement of Alexei Navalny in 2017-2018. The main actions of the movement and the reaction of the authorities to them are described and evaluated.

Keywords: protest, political protest, collective action, Navalny, social movement

\section{Источники и литература}

Документы и правовые акты:

Федеральный закон от 10.01.2003 №79-Ф3 «0 выборах Президента Российской Федерации».

Справочная система «Консультант-Плюс» http://www.consultant.ru/document/cons_doc_ LAW_40445/

Постановление Центральной избирательной комиссии Российской Федерации от 25.12.2017 г. №178/973-7 «0б отказе в регистрации группы избирателей, созданной для поддержки самовыдвижения кандидата на должность Президента Российской Федерации Алексея Анатольевича Навального, и его уполномоченных представителей, Официальный сайт ЦИК РФ, http://www. cikrf.ru/activity/docs/postanovleniya/30868/

Сводные финансовые отчеты политических партий за 2017 год, Центральная избирательная комиссия Российской Федерации, http://cikrf.ru/politparty/finance/svodn_otchet_17.php 
Pobrane z czasopisma Wschód Europy http://journals.umcs.pl/we

Data: 26/04/2023 15:58:18

Общественное движение Алексея Навального в России: ресурсы, тактика и перспективы

\section{Монографии:}

Tarrow S., Power in Movement. Social Movement and Contentious Politics, Cambridge University Press, 2011.

\section{Интернет источники:}

Баринов М., Навальный привлечен в качестве третьего лица к иску о блокировке «Умного голосования», 14.12.2018, https://www.kommersant.ru/doc/3832979

Волков Д., Не только большие протесты, „Ведомости”, 06.05.2018, https://www.vedomosti.ru/ opinion/articles/2018/05/07/768724-ne-bolshie-protesti

Дебаты Навального и Собчак, 18.03.2018, https://www.youtube.com/watch?v=gQeAy2ytMnU

Дмитриев М., Белановский С., Никольская А., Признаки изменения общественных настроений и их возможные последствия, Комитет гражданских инициатив, 11.10.2018, https://komitetgi. ru/news/news/3902/

Доверие политикам, Рейтинги и индексы Всероссийского центра изучения общественного мнения (ВЦИОМ), https://wciom.ru/news/ratings/doverie_politikam/

Итоги-2018, https://navalny.com

Июньские протесты не добавили Навальному популярности, 17.07.2017, Левада-Центр, https:// www.levada.ru/2017/07/17/iyunskie-protesty-ne-dobavili-navalnomu-populyarnosti/

Кремль на развилке, 26.03.2017, РБК, https://www.rbc.ru/politics/26/03/2017/58d7c6f39a7947448 a1a3f45

Литой А., Акции против «царя»: избитые, задержанные, несовершеннолетние, ОВД - Инфо, 08.05.2018, https://ovdinfo.org/articles/2018/05/08/akcii-protiv-carya-izbitye-zaderzhannye-nesovershennoletnie

Махаметшина Е., Навальный прокомментировал выдвижение Собчак в президенты, Ведомости, 26.10.2017, https://www.vedomosti.ru/politics/articles/2017/10/26/739569-navalnii-sobchak

Мониторинг самочувствия регионов: ситуация на июль 2018 г. и её развитие, Комитет гражданских инициатив, https://komitetgi.ru/analytics/3946/

Навального арестовали на 30 суток, РБК, 27.08.2018, https://www.rbc.ru/society/27/08/2018/5b83 a57b9a7947543b7aa26f?from=main

Навальный 20!8, https://2018.navalny.com

Навальный LIVE-2019. Что с женской аудиторией?, https://navalny.com

Осенний перелом в сознании россиян: мимолетный всплеск или новая тенденция?, Фонд «Либеральная миссия», 26.12.2018, http://www.liberal.ru/articles/7298

Официальный портал Центрального казачьего войска, 07.05.2018, http://vko-ckv.ru/novosti/ ofitsialno.html

Петров Н., Политические переменные: с чем столкнется российская власть в 2019 году, 06.01.2019, РБК, https://www.rbc.ru/opinions/politics/06/01/2019/5c2491e49a794778e758e398

Протестный потенциал, Всероссийский центр изучения общественного мнения, https://wciom.ru/ news/ratings/protestnyj_potencial/

Протесты 5-го мая, Левада-Центр, 06.06.2018, https://www.levada.ru/2018/06/06/protesty-5-gomaya/ 
Pobrane z czasopisma Wschód Europy http://journals.umcs.pl/we

Data: 26/04/2023 15:58:18

Путин объявил о смягчении условий пенсионной реформы, „Ведомости”, 29.08.2018, https://www. vedomosti.ru/economics/articles/2018/08/29/779297-putin-teleobraschenie

Родин И., Штабы Навального стали политическими центрами, „Независимая газета”, 09.01.2019, http://www.ng.ru/politics/2019-01-09/1_7477_navalny.html

Россияне не верят в протесты, Левада-центр, 28.09.2017, https://www.levada.ru/2017/09/28/ rossiyane-ne-veryat-v-protesty/

Рост протестной активности в России: результаты всероссийского мониторинга 2017-2018 гг., Центр экономическихиполитических реформ, http://cepr.su/2018/11/08/protests-2017-2018/ Умное голосование, https://2019.vote

Эксперты КГИ представили итоги мониторинга социально-экономической и политической напряженности регионов за три года, Комитет гражданских инициатив, 20.06.2018, https:// komitetgi.ru/analytics/3797/

XVIII Съезд «Единой России», 9.12.2018, https://er.ru/core/news/subject/145.html 